\title{
Application of the Plan-Do-Check-Act Cycle for Managing Immune- Related Adverse Events
}

\author{
Satoshi Hibi ${ }^{1,6}$, Yuko Shirokawa ${ }^{2,6}$, Kengo Nanya ${ }^{3,6}$, Yuko Kato ${ }^{4,6}$, Nobuto Ito \\ Takae Kataoka ${ }^{5}$, Takashi Yoshida ${ }^{5,6}$, Yoshiaki Marumo, Satoshi Kayukawa ${ }^{5,6}$, \\ Shu Yuasa ${ }^{1}$, Yoshiteru Tanaka ${ }^{7}$ and Kenji Ina ${ }^{7^{*}}$ \\ ${ }^{1}$ Department of Hospital Pharmacy, Nagoya Memorial Hospital, Japan \\ ${ }^{2}$ Department of Nursing, Nagoya Memorial Hospital, Japan \\ ${ }^{3}$ Department of Clinical Laboratory, Nagoya Memorial Hospital, Japan \\ ${ }^{4}$ Medical Social Work Consultation Room, Nagoya Memorial Hospital, Japan \\ ${ }^{5}$ Department of Clinical Oncology, Nagoya Memorial Hospital, Japan \\ ${ }^{6}$ Chemotherapy team, Nagoya Memorial Hospital, Japan \\ ${ }^{7}$ Shinseikai Daiichi Hospital, Nagoya, Japan
}

\begin{abstract}
Background: Immune checkpoint inhibitors (ICls) sometimes cause immune-related adverse events (irAEs), the timing of occurrence of which is difficult to predict. We created a system to safely manage the patients treated with $\mathrm{ICls}$ who visit hospital during an emergency.

Methods: We utilized the Plan-Do-Check-Act (PDCA) cycle method to improve the quality of countermeasures for irAEs in the emergency room. First, an icon showing the patients treated with ICls was developed for inclusion in electronic medical records. Second, ICl-specified urgent sets of clinical laboratory tests were prepared to cover the spectrum of irAEs. Third, a direct call system to either the attending physician or the chemotherapy team was established. A flow chart for managing irAEs has been prepared since September 2018. We retrospectively analyzed the electronic medical records from September 2018 to December 2020 to determine the effectiveness of the developed system.

Results: In the first cycle of PDCA, 24 patients administered ICls were retrospectively surveyed and seven visited the emergency room. Six cases were examined according to the flow chart, whereas the other patient complaining of grade 2 diarrhea were not examined because of incomplete knowledge regarding ICls and irAEs. As part of the "Act" step, we reminded the doctors of the flow chart and gave a lecture to the residents on how to manage irAEs. During the second and seventh cycle, no cases were observed without consulting the flow chart.

Conclusions: Quality improvement activities for the management of irAEs were conducted using the PDCA cycle methodology. Patients on ICls are now being continuously monitored to further improve management quality.
\end{abstract}

Keywords: Immune checkpoint inhibitor, immune-related adverse event, Plan-Do-Check-Act cycle, emergency room, quality improvement, multidisciplinary team.

\section{BACKGROUND}

Immune checkpoint inhibitors (ICls) have revolutionized cancer therapy and significantly prolonged the survival of patients with the specific types of cancer [1-5]. However, these inhibitors can also trigger autoimmune reactions referred to as immune-rerated adverse events (irAEs), and include skin rash, enterocolitis, pneumonitis, and endocrine disorders $[6,7]$.

With expansion in the approved uses of $\mathrm{ICls}$ for many types of cancer, irAEs have been observed in

*Address correspondence to this author at the Department of Geriatric Medicine, Shinseikai Daiichi Hospital, 1302 Takamiya, Tempaku-ku, Nagoya 468-0031, Japan; Tel: +81-52-808-2100; Fax: +81-52-808-3232;

E-mail: kina@hospy.or.jp multiple organs during or even after the end of $\mathrm{ICl}$ treatment. Because general physicians as well as medical oncologists encounter patients treated with $\mathrm{ICls}$ in the clinical setting, managing such patients has become common practice in the emergency room (ER).

Therefore, we aimed to improve the quality of chemotherapy concerning $\mathrm{ICl}$ and management of these patients during emergency visits. We utilized the Plan-Do-Check-Act (PDCA) cycle method [8, 9], which has been reported as useful one for improving quality management of infectious disease, but not in cancer medicine. So, our approach using PDCA cycle method is helpful as a model to improve not only $\mathrm{ICI}$ treatment but also cancer medical areas. 


\section{METHODS}

A pilot study was conducted to investigate the medical records of patients treated with $\mathrm{ICls}$ who visited ER from February 2016 to December 2017. The chemotherapy team exchanged opinions with the doctors who encountered these patients. Through this survey, the following points were noted.

\# Sharing information on the administration history of $\mathrm{ICls}$ during an emergency visit is crucial.

\# Detection of irAEs, particularly endocrine disorders, based on patient complaints of symptoms is difficult.

\# $\quad$ Residents who typically have a first approach for patients in the ER are unfamiliar with either ICI treatment or irAEs.

\# There is no consultation system regarding irAEs when the attending physician is off duty.

These problems were reviewed by the chemotherapy team, and the PDCA cycle was implemented as follows.

\section{Plan}

I. An icon should be included in the electronic medical records to show which patients are currently or were previously administered ICls.

II. ICl-specified urgent sets of clinical laboratory tests should be performed to cover the spectrum of irAEs.

III. A direct call system should be made, starting with the attending physician or chief doctor of the same department, followed by the chemotherapy team.

IV. This information should be disseminated to all medical staff.

Do

I. We developed an icon for inclusion in electronic medical records to show which patients were treated with ICls (Figure 1).

II. Urgent sets of clinical laboratory tests were prepared through collaboration of the chemotherapy team and Department of Medical Safety Management (Table 1A).
III. A flow chart of the direct call system was prepared in September 2018 (Figure 2).

IV. We informed all medical staff of the flow chart at the doctors' office and head nurses' committee and disseminated the chart using the local network system.

\section{Check}

I. These plans are assessed every 4 months by investigating the electronic medical records of patients who visited the ER.

Act

I. The assessment is reviewed by the chemotherapy team. Any new or unresolved concerns are incorporated into the next cycle to improve the process.

\section{RESULTS}

The ICls used in Nagoya Memorial Hospital are listed in Table 2. Our preliminary survey before planning the PDCA cycle revealed that 32 patients were treated with $\mathrm{ICls}$ and 4 patients had emergency visits. Residents first saw these patients at the ER and then consulted with a senior doctor on duty or chief physicians. These cases were handled appropriately without incident; however, there was a request for a system tool to describe the administration history of ICls. As a plan for the PDCA cycle, an icon showing which patients had been treated with ICls was included in the electronic medical records in September 2018 based on the request (Figure 1). This icon is shown on the top window of the medical record, and can be immediately recognized by the medical staff. Second, $\mathrm{ICl}$-specified urgent sets of clinical laboratory tests were prepared to cover the spectrum of irAEs (Table 1A). Third, the flow chart of a direct call system was prepared (Figure 2). We informed all doctors and nurses of this flow chart at the doctors' office and head nurses' committee and disseminated this information using the local network system.

In the first cycle of PDCA between September and December 2018, 24 patients were treated with ICls and seven visited the hospital because of an emergency. The reasons for visiting the ER were infection in two cases, irAEs in two cases, disease burden in two cases, and tumor pain in one case. Six cases were evaluated according to the flow chart, whereas one case with grade 2 diarrhea was not examined at the 


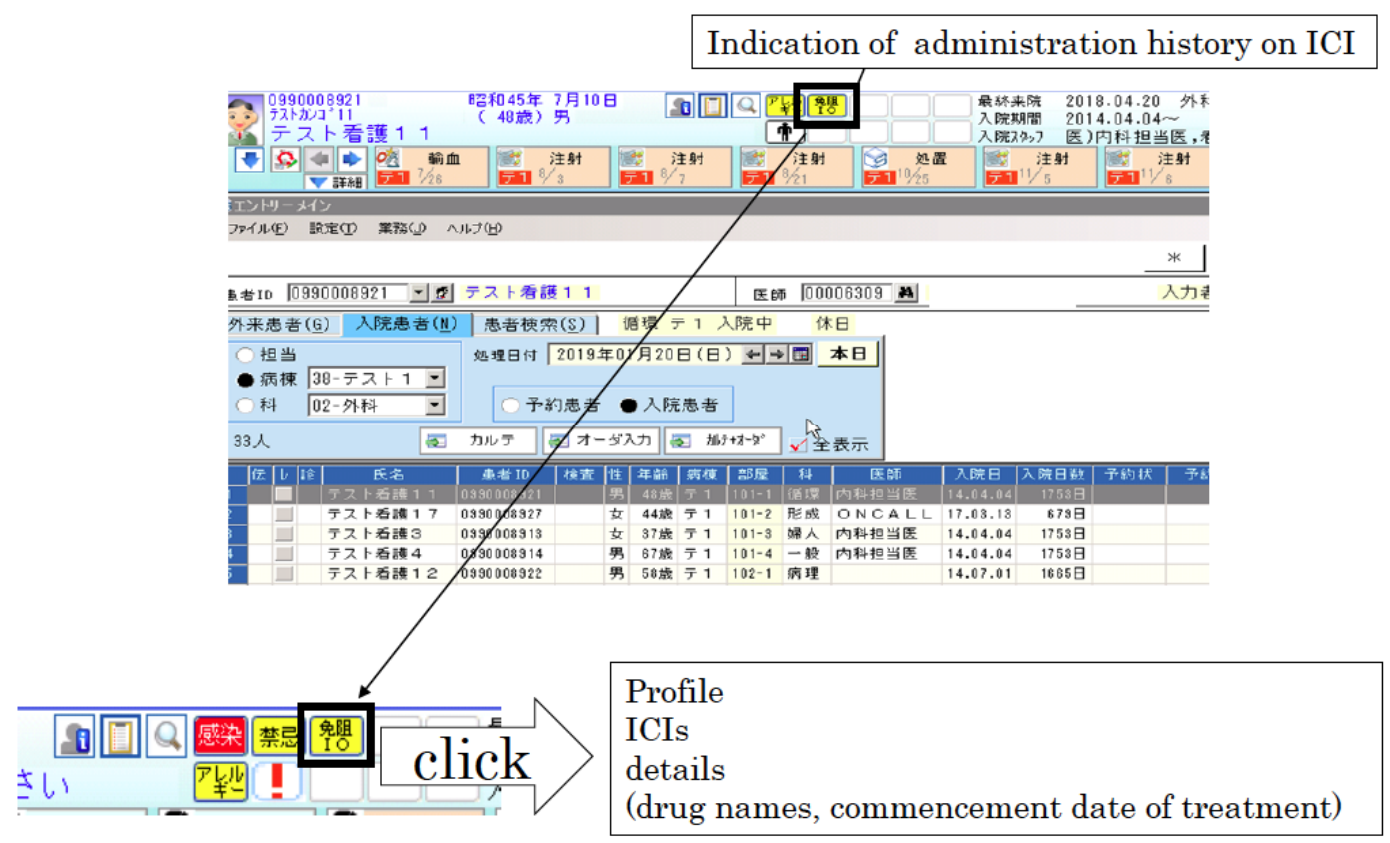

Figure 1: Electronic medical record icon showing patients treated with ICls.

1. Ensure the administration history of ICIs based on the icon in the electronic records.

2. Carry out urgent sets of clinical examination if the patient has a symptom of irAE and consult with a senior doctor on duty.

In case of difficulty in the management of patients on ICIs,

(1) Consult the attending physician or a chief doctor in the same department

(2) Consult doctors on the chemotherapy team (two medical oncologists) without hesitation

Figure 2: Flow chart of direct call system to manage irAEs.

emergency department because knowledge on $\mathrm{ICls}$ and irAEs was incomplete. We reminded the doctors to use this flow chart at doctors' office committee again, and gave a lecture to residents who encountered patients in the emergency department on the importance of irAEs and how to manage these patients. From the second to seventh cycle of the PDCA, some patients had emergency visits in each cycle (Table 3 ), and all patients were appropriately handled according to the manual.

Through discussion with the multidisciplinary chemotherapy team, we applied countermeasures for earlier detection of irAEs. First, we created an irAEspecific test set in February 2018 which was performed periodically before and after starting $\mathrm{ICl}$ treatment
(Table 1B,C). In the fourth cycles of PDCA (September to December 2019), the rates of ICl-specific testing were examined for each department; the rates before and after introduction of the irAE-specific test set were compared. Before initiating $\mathrm{ICl}$ treatment, the check rate of thyroid-stimulating hormone (TSH), free triiodothyronine $\left(\mathrm{FT}_{3}\right)$, free thyroxine $\left(\mathrm{FT}_{4}\right)$, and KrebsvonderLungen-6 (KL-6) was $92 \%$, which was the same as before introduction of the test set (Table 4). The check rates of hemoglobin A1c ( $\mathrm{HbA1c})$, cortisol, and adrenocorticotropic hormone (ACTH) increased from $62 \%$ to $89 \%, 69 \%$ to $100 \%$, and $46 \%$ to $100 \%$, respectively. After initiating $\mathrm{ICl}$ treatment, the check rates of $\mathrm{TSH}, \mathrm{FT}_{3}$, and $\mathrm{FT}_{4}$ were the same (92\%), and those of KL-6, surfactant protein D (SP-D), and HbA1c improved from $54 \%$ to $65 \%, 46 \%$ to $54 \%$, and $54 \%$ to 
Table 1: ICI-Specific Test Set

\begin{tabular}{|c|c|}
\hline A. Urgent set of clinical laboratory tests & Test item \\
\hline Disease & TSH, FT3, FT4 \\
\hline \hline Thyroid disease & KL-6, SP-D, Chest X-ray \\
\hline Interstitial lung disease & HbA1c \\
\hline Diabetes mellitus & Cortisol, ACTH \\
\hline Adrenal insufficiency, Hypophysitis & ECG \\
\hline Myocarditis &
\end{tabular}

B. Set before starting ICI treatment.

\begin{tabular}{|c|c|}
\hline Disease & Test item \\
\hline \hline Thyroid disease & TSH, FT3, FT4 \\
\hline Interstitial lung disease & KL-6, SP-D, Chest X-ray \\
\hline Diabetes mellitus & Cortisol, ACTH \\
\hline Adrenal insufficiency, Hypophysitis & ECG \\
\hline Myocarditis & \\
\hline
\end{tabular}

\section{Set after starting $\mathrm{ICI}$ treatment.}

\begin{tabular}{|c|c|}
\hline \hline Disease & Test item \\
\hline Thyroid disease & TSH, FT3, FT4 \\
\hline Interstitial lung disease & KL-6, SP-D \\
\hline Diabetes mellitus & HbA1c \\
\hline
\end{tabular}

ICl: immune checkpoint inhibitor, TSH: thyroid-stimulating hormone, $\mathrm{FT}_{3}$ : free triiodothyronine, $\mathrm{FT}_{4}$ : free thyroxin; KL-6: Krebs von der Lungen-6, SP-D: surfactant protein D, HbA1c: hemoglobin A1c, ACTH: adrenocorticotropic hormone, ECG: electrocardiogram.

Table 2: Immune Checkpoint Inhibitors that have been used at Nagoya Memorial Hospital

\begin{tabular}{|c|c|c|c|}
\hline \multirow[t]{4}{*}{ Anti-PD-1 antibody } & \multirow[t]{3}{*}{ Nivolumab } & Lung & Respiratory Medicine \\
\hline & & Lymphoma & Clinical Oncology \\
\hline & & Renal & Urology \\
\hline & Pembrolizumab & Bladder & Medical Oncology \\
\hline \multirow[t]{2}{*}{ Anti-PD-L1-antibody } & Atezolizumab & Lung & Respiratory Medicine \\
\hline & Durvalumab & Lung & Respiratory Medicine \\
\hline
\end{tabular}

Anti-PD-1 antibody: anti-programmed cell death 1 antibody.

Anti-PD-L1 antibody: anti-programmed cell death-ligand 1 antibody.

$62 \%$ (Table 5), but were not sufficient even after introduction of irAE-specific test set. These results indicate that doctors were generally not aware that irAEs, including endocrine disorders, can occur at any time. Therefore, continuous monitoring was initiated by the chemotherapy team to check the implementation of the irAE-specific test. If the test set was not scheduled by doctors, the chemotherapy team reminded the attending doctors to order a test set every month. In the "Act" step of the PDCA, we gave a lecture to new 
Table 3: Check of PDCA Cycle

\begin{tabular}{|c|c|c|c|c|c|}
\hline Cycle & Durations & Patients on ICI & $\begin{array}{l}\text { Emergency } \\
\text { visit }\end{array}$ & Reasons & irAEs \\
\hline 1 & $\begin{array}{c}\text { September- } \\
\text { December, } 2018\end{array}$ & 24 & 7 & $\begin{array}{l}\text { Infection(2) } \\
\text { irAE(2) } \\
\text { Tumor burden(2) } \\
\text { Tumor pain(1) }\end{array}$ & $\begin{array}{l}\text { Diarrhea (grade 2) } \\
\text { Vomiting (grade 3) }\end{array}$ \\
\hline 2 & January-April, 2019 & 24 & 7 & $\begin{array}{l}\text { Infection (3) } \\
\text { irAE (2) } \\
\text { Tumor pain (1) } \\
\text { Cough (1) }\end{array}$ & $\begin{array}{c}\text { Adrenal insufficiency (grade 2) } \\
\text { Nausea (grade 1) }\end{array}$ \\
\hline 3 & May-August, 2019 & 25 & 5 & $\begin{array}{c}\text { Infection(2) } \\
\text { irAE(1) } \\
\text { Tumor burden(1) } \\
\text { Underlying disease burden(1) }\end{array}$ & $\begin{array}{l}\text { Acute renal failure } \\
\quad \text { (grade } 3)\end{array}$ \\
\hline 6 & May-August, 2020 & 27 & 6 & $\begin{array}{l}\text { Infection (5) } \\
\text { irAE (1) }\end{array}$ & $\begin{array}{l}\text { Adrenal insufficiency } \\
\text { (grade 3) }\end{array}$ \\
\hline 7 & $\begin{array}{c}\text { September- } \\
\text { December, } 2020\end{array}$ & 26 & 6 & $\begin{array}{c}\text { Infection (1) } \\
\text { irAE (1) } \\
\text { Tumor burden (2) } \\
\text { Underlying disease burden (2) }\end{array}$ & $\begin{array}{l}\text { Diarrhea } \\
\text { (grade 1) }\end{array}$ \\
\hline
\end{tabular}

irAEs: immune-related adverse events.

Table 4: Comparison of Check Rates before Starting ICI Treatment between Pre- and Post-Introduced ICI-Specific Test Set

\begin{tabular}{|c|c|c|c|c|c|}
\hline Test item & & Total (\%) & Respiratory Medicine (\%) & Urology (\%) & Medical Oncology (\%) \\
\hline TSH & pre & 92 & 100 & 100 & 67 \\
\hline \multirow[t]{2}{*}{ FT3 } & pre & 92 & 100 & 100 & 67 \\
\hline & post & 92 & 94 & 100 & 100 \\
\hline FT4 & pre & 92 & 100 & 100 & 67 \\
\hline \multirow[t]{2}{*}{ KL-6 } & pre & 92 & 100 & 75 & 100 \\
\hline & post & 92 & 100 & 60 & 100 \\
\hline \multirow[t]{2}{*}{ SP-D } & pre & 77 & 83 & 50 & 100 \\
\hline & post & 73 & 60 & 100 & 100 \\
\hline $\mathrm{HbA1c}$ & pre & 62 & 50 & 67 & 67 \\
\hline \multirow[t]{2}{*}{ ACTH } & pre & 46 & 100 & 0 & 33 \\
\hline & post & 100 & 100 & 100 & 100 \\
\hline \multirow[t]{2}{*}{ Chest X-ray } & pre & 100 & 100 & 100 & 100 \\
\hline & post & 100 & 100 & 100 & 100 \\
\hline \multirow[t]{2}{*}{ ECG } & pre & 69 & 83 & 25 & 100 \\
\hline & post & 92 & 89 & 100 & 100 \\
\hline
\end{tabular}

TSH: thyroid-stimulating hormone, $\mathrm{FT}_{3}$ : free triiodothyronine, $\mathrm{FT}_{4}$ : free thyroxin; $\mathrm{KL}-6$ : Krebs von der Lungen-6, SP-D: surfactant protein $\mathrm{D}$, HbA1c: hemoglobin $\mathrm{A} 1 \mathrm{c}$, ACTH: adrenocorticotropic hormone, ECG: electrocardiogram. 
Table 5: Comparison of Check Rates after Starting ICI Treatment between Pre- and Post-Introduced ICI-Specific Test Set

\begin{tabular}{|c|c|c|c|c|c|}
\hline Test item & & Total $(\%)$ & Respiratory Medicine (\%) & Urology (\%) & Medical Oncology (\%) \\
\hline TSH & pre & 92 & 100 & 100 & 67 \\
\hline \multirow[t]{2}{*}{ FT3 } & pre & 92 & 100 & 100 & 67 \\
\hline & post & 92 & 100 & 80 & 100 \\
\hline FT4 & post & 92 & 100 & 80 & 100 \\
\hline \multirow[t]{2}{*}{ KL-6 } & pre & 54 & 67 & 25 & 100 \\
\hline & post & 65 & 50 & 80 & 100 \\
\hline SP-D & pre & 46 & 67 & 0 & 67 \\
\hline
\end{tabular}

TSH: thyroid-stimulating hormone, $\mathrm{FT}_{3}$ : free triiodothyronine, $\mathrm{FT}_{4}$ : free thyroxin; $\mathrm{KL}-6$ : Krebs von der Lungen-6, SP-D: surfactant protein $\mathrm{D}$, HbA1c: hemoglobin $\mathrm{A} 1 \mathrm{c}$, ACTH: adrenocorticotropic hormone.

Table 6: Immune-Rerated Adverse Events in Outpatient Setting from September 2018 to December 2020

\begin{tabular}{|c|c|c|c|c|}
\hline \multirow[t]{2}{*}{ irAEs } & \multicolumn{4}{|c|}{ Grade } \\
\hline & 1 & 2 & 3 & 4 \\
\hline Nausea & 2 & & & \\
\hline Vomiting & 2 & & 1 & \\
\hline Anorexia & 2 & 2 & 1 & \\
\hline Diarrhea & 2 & 3 & & \\
\hline Rash & 2 & 4 & & \\
\hline Hypothyroidism & & 6 & & \\
\hline Hyperthyroidism & 2 & & & \\
\hline Adrenal insufficiency & & 3 & 1 & \\
\hline Acute renal failure & & 1 & 1 & \\
\hline Pneumonitis & & 1 & & 1 \\
\hline Panniculitis & & 1 & & \\
\hline Ventricular arrhythmia & & 1 & & \\
\hline
\end{tabular}

residents and continuous monitoring was performed by the chemotherapy team.

In the fifth cycle (January to April 2020), 26 patients were administered $\mathrm{ICls}$ and 3 patients visited the hospital for an emergency. The reasons for visiting the ER were tumor burden in one case and underlying disease burden in two cases. The implementation rates of irAE-specific testing gradually increased to $89 \%$ for TSH, $\mathrm{FT}_{3}$, and $\mathrm{FT}_{4} ; 78 \%$ for $\mathrm{KL}-6$ and SP-D; and $67 \%$ for $\mathrm{HbA1c}$. The doctors intentionally did not order these tests each month because health insurance may not cover the cost of $\mathrm{ICl}$-specific testing once per month. Accordingly, we encouraged the physicians to 
implement $\mathrm{ICl}$-specific testing every other month. In addition, based on academic society reports [10-12], cortisol, ACTH, and general urine tests were added to the follow-up test set.

In the sixth cycle $(n=27)$, six patients visited the ER for infection in five cases and an irAE in one case. One patient with an irAE had grade 3 adrenal insufficiency and was treated according to the manual, leading to hospitalization. In the seventh cycle $(n=26)$, six patients visited the ER for infection in one case, irAE (grade 1 diarrhea) in one case, tumor burden in 2 cases, and underlying disease burden in 2 cases.

In the second to seven cycle, all cases were handled according to the manual, implementing the action to inform doctors and residents suitably of the flowchart and management of irAE.

From September 2018 to December 2020, ICls were administered to 46 patients with cancer in outpatient settings. Among them, 28 patients developed irAEs as shown in Table 6. These irAEs were diagnosed at either periodical consultation or emergency visit. Among them, $82 \%$ (23 patients) were mild to moderate irAEs, but $18 \%$ (5 patients), severe more than grade 3 .

\section{DISCUSSION}

We aimed to improve the quality of treatment with ICls using the PDCA cycle method. Although there are several reports on using the PDCA cycle method to improve the quality management of infectious disease $[8,9]$, few are available in the oncology field.

Guidelines for managing irAEs are available in western countries $[13,14]$. As irAEs can occur at any time, either during treatment with ICls or even after discontinuation of treatment, the patients must be continuously and closely monitored [6, 7]. In addition, the indication for $\mathrm{ICl}$ therapy has been extensively expanded, increasing the number of patients being administered ICls. Therefore, more patients treated with ICls are expected to visit the hospital for emergencies. In our hospital, residents inexperienced in cancer medicine often have a first approach to such patients in the ER. To improve the quality irAE management, four countermeasures were planned and implemented in the first cycle of the PDCA. In analyzing the first cycle of the PDCA, we found that a patient complained of grade 2 diarrhea during visits to the ER at night, and returned home only with symptomatic treatment but no specific examinations or consultations with a senior doctor. As this incident was mainly caused by the resident's lack of awareness of irAEs, several lectures were held to inform the residents of how to manage irAEs as the "Act" step.

In Table 6, three patients were directly admitted to our hospital because of grade 3 irAEs such as anorexia, vomit, acute renal failure and adrenal insufficiency. All patients eventually recovered from the irAEs because of the early diagnosis and treatment. Two patients with severe-grade irAEs, pneumonitis and type 1 fulminant diabetes mellitus, did not come to the ER but rather attended outpatient consultation appointments. A patient had developed grade 4 pneumonitis by the time he had been consulted on his reserved outpatient day and was hospitalized. Considering these cases, patients should be also educated on irAEs and the importance of undergoing medical examination as soon as possible before developing a severe condition. Moreover, three patients consulted their family doctors before visiting our hospital; thus, to manage patients with cancer being administered ICls, it is important to share information and cooperate with local clinics.

\section{CONCLUSIONS}

We conducted quality improvement activities with a multidisciplinary team for managing irAEs, particularly in cases of emergency visits. Successful management of irAEs should involve early diagnosis and close monitoring of patients administered ICls. Use of the PDCA cycle method will contribute to improving the quality and security of $\mathrm{ICI}$ treatment.

\section{LIST OF ABBREVIATIONS}

$$
\begin{array}{ll}
\mathrm{ICl} & =\text { immune checkpoint inhibitor } \\
\mathrm{irAE} & =\text { immune-related adverse event } \\
\mathrm{PDCA} \text { cycle } & =\text { Plan-Do-Check-Act cycle } \\
\mathrm{ER} & =\text { emergency room } \\
\mathrm{TSH} & =\text { thyroid-stimulating hormone } \\
\mathrm{FT}_{3} & =\text { free triiodothyronine } \\
\mathrm{FT}_{4} & =\text { free thyroxin } \\
\mathrm{KL}-6 & =\text { Krebsvonder Lungen-6 } \\
\mathrm{HbA} 1 \mathrm{c} & =\text { hemoglobin } \mathrm{A}_{1 \mathrm{c}}
\end{array}
$$




$$
\begin{array}{ll}
\text { SP-D } & =\text { surfactant protein } D \\
\text { ACTH } & =\text { adrenocorticotropic hormone }
\end{array}
$$

\section{DECLARATIONS}

Ethics approval and consent to participate.

The protocol of this study was approved by the ethics committee of Nagoya Memorial Hospital (approval No. 2021-007) and conducted in accordance with the Declaration of Helsinki.

\section{CONSENT FOR PUBLICATION}

Not applicable.

\section{AVAILABILITY OF DATA AND MATERIALS}

All data generated or analyzed during this study are included in this published article.

\section{COMPETING INTERESTS}

The authors declare that they have no competing interests.

\section{FUNDING}

Not applicable.

\section{AUTHORS' CONTRIBUTIONS}

$\mathrm{SH}, \mathrm{KI}$ wrote the manuscript. SH reviewed the medical records. All authors read and approved the final manuscript.

\section{ACKNOWLEDGEMENTS}

Not applicable.

\section{REFERENCES}

[1] Hellmann MD, Paz-Ares L, Bernabe Caro R, Zurawski B, Kim SW, Carcereny Costa E, et al. Nivolumab plus Ipilimumab in Advanced Non-Small-Cell Lung Cancer. N Engl J Med 2019; 21: 2020-2031. https://doi.org/10.1056/NEJMoa1910231

[2] Melosky B, Juergens R, Hirsh V, McLeod D, Leighl N, Tsao MS, et al. Amplifying Outcomes: Checkpoint Inhibitor Combinations in First-Line Non-Small Cell Lung Cancer. Oncologist 2020; 1: 64-77. https://doi.org/10.1634/theoncologist.2019-0027
[3] Brahmer J, Reckamp KL, Baas P, Crinò L, Eberhardt WE, Poddubskaya $\mathrm{E}$, et al. Nivolumab versus Docetaxel in Advanced Squamous-Cell Non-Small-Cell Lung Cancer. N Engl J Med 2015; 2: 123-135.

\section{https://doi.org/10.1056/NEJMoa1504627}

Chau I, Ayers D, Goring S, Cope S, Korytowsky B, Abraham $P$. Comparative effectiveness of nivolumab versus clinical practice for advanced gastric or gastroesophageal junction cancer. J Comp Eff Res 2020; 2: 103-114. https://doi.org/10.2217/cer-2019-0145

[5] Motzer RJ, Tannir NM, McDermott DF, ArénFrontera O Melichar B, Choueiri TK, et al. Nivolumab plus Ipilimumab versus Sunitinib in Advanced Renal-Cell Carcinoma. N Engl J Med 2018; 14: 1277-1290. https://doi.org/10.1056/NEJMoa1712126

[6] Michot JM, Bigenwald C, Champiat S, Collins M, Carbonnel F, Postel-Vinay S, et al. Immune-related adverse events with immune checkpoint blockade: a comprehensive review. Eur J Cancer 2016; 54: 139-148. https://doi.org/10.1016/j.ejca.2015.11.016

[7] Spain L, Diem S, Larkin J. Management of toxicities of immune checkpoint inhibitors. Cancer Treat Rev 2016; 44: 51-60.

https://doi.org/10.1016/j.ctrv.2016.02.001

[8] Chen Y, Zheng J, Wu D, Zhang Y, Lin Y. Application of the PDCA cycle for standardized nursing management in a COVID-19 intensive care unit. Ann Palliat Med 2020; 3: 1198-1205 https://doi.org/10.21037/apm-20-1084

[9] Kong X, Zhu X, Zhang Y, Wu J. The application of plan, do, check, act (PDCA) quality management in reducing nosocomial infections in endoscopy rooms: It does work. Int $\mathrm{J}$ Clin Pract 2021; 10: 14351. https://doi.org/10.1111/ijcp.14351

[10] Grouthier V, Lebrun-Vignes B, Moey M, Johnson DB Moslehi JJ, Salem JE, et al. Immune Checkpoint InhibitorAssociated Primary Adrenal Insufficiency: WHO VigiBase Report Analysis Oncologist 2020; 8: 696-701. https://doi.org/10.1634/theoncologist.2019-0555

[11] González-Rodríguez E, Rodríguez-Abreu D. Spanish Group for Cancer Immuno-Biotherapy (GETICA). Immune Checkpoint Inhibitors: Review and Management of Endocrine Adverse Events. Oncologist 2016; 7: 804-816. https://doi.org/10.1634/theoncologist.2015-0509

[12] Shingarev R, Glezerman IG. Kidney Complications of Immune Checkpoint Inhibitors: A Review. Am J Kidney Dis 2019; 4: 529-537. https://doi.org/10.1053/i.ajkd.2019.03.433

[13] Brahmer JR, Lacchetti C, Schneider BJ, Atkins MB, Brassi $\mathrm{KJ}$, Caterino JM, et al. Management of Immune-Related Adverse Events in Patients Treated With Immune Checkpoint Inhibitor Therapy: American Society of Clinical Oncology Clinical Practice Guideline. J Clin Oncol 2018; 17: 1714 1768.

https://doi.org/10.1200/JCO.2017.77.6385

[14] Haanen JBAG, Carbonnel F, Robert C, Kerr KM, Peters S, Larkin J, Jordan K. Management of toxicities from immunotherapy: ESMO Clinical Practice Guidelines for diagnosis, treatment and follow-up. Ann Oncol 2017; 28: 119-142.

https://doi.org/10.1093/annonc/mdx225

\section{https://doi.org/10.30683/1927-7229.2021.10.06}

(c) 2021 Hibi et al.; Licensee Neoplasia Research.

This is an open access article licensed under the terms of the Creative Commons Attribution Non-Commercial License (http://creativecommons.org/licenses/by-nc/3.0/) which permits unrestricted, non-commercial use, distribution and reproduction in any medium, provided the work is properly cited. 